\section{Estigma Social e saúde de mulheres com deficiência: um diálogo acerca da iniquidade}

\section{David, Renata Bernardes}

Mestranda, Programa de Pós-Graduação em Políticas Públicas em Saúde, Fundação Oswaldo Cruz (Fiocruz), Brasília, Brasil. e-mail: renata.david@ fiocruz.br

\section{Tomasini, Ana Júlia}

Doutoranda, Cátedra Unesco de Bioética da Universidade de Brasília (UnB), Brasil.

\section{Barros, Flora Campos}

Mestranda, Mestrado Profissional em Preservação do Patrimônio Cultural do IPHAN, Brasília, Brasil.

\section{Köptcke, Luciana Sepúlveda}

PhD, Programa de Pós-Graduação em Políticas Públicas em Saúde, Fundação Oswaldo Cruz (Fiocruz), Brasília, Brasil.

\section{Pinto, Alexandro Rodrigues}

Mestre, Programa de Pós-Graduação em Políticas Públicas em Saúde, Fundação Oswaldo Cruz (Fiocruz), Brasília, Brasil.

PALAVRAS-CHAVE: Estigma Social, Iniquidades em Saúde, Acesso aos Serviços de Saúde, Pessoas com Deficiência.

INTRODUÇÃO Este trabalho descreve o acesso à saúde por mulheres com deficiência $(\mathrm{McD})$ à luz do conceito de estigma de Goffman ${ }^{1}$, a partir da Pesquisa Nacional de Saúde (PNS). O perfil da morbimortalidade e do acesso à saúde são impactados pelas desigualdades de gênero, sob o aspecto dos atributos biológicos e culturais, bem como os agravos à saúde decorrentes da associação entre estereótipos de gênero e estigmas específicos, e acabam por comprometer o exercício da cidadania, sobretudo relacionado ao direito à saúde $^{2,3}$. Goffman ${ }^{1}$ associou estigma a doenças incapacitantes, distúrbios mentais e doenças infectocontagiosas, relacionando-o à característica do sujeito que, transformada socialmente em atributo negativo, desqualifica-o, criando obstáculos ao acesso de bens materiais e simbólicos. A definição das marcas que operam como estigmas não é arbitrária, relaciona-se a situações ou característica com eixos sociais de produção de desigualdades. McD são, dessa forma, mais vulneráveis aos desafios decorrentes das necessidades de cuidados de saúde, e, frequentemente, apresentam-se em situação de pobreza ${ }^{4}$. Embora historicamente serviços de saúde privilegiem a clientela feminina, pouco reconhecem em relação à dupla vulnerabilidade que acometem as $\mathrm{McD}^{2,3}$. O conceito de acesso é complexo e, geralmente, empregado de forma imprecisa na relação com o uso de serviços de saúde. O acesso à saúde está relacionado à resistência que os serviços proporcionam para que sejam alcançados, entendida como a dificuldade na obtenção dos serviços de saúde ${ }^{4}$, determinante para a saúde das McD. A análise a partir da bioética proporciona o questionamento da ordem social estabelecida e a inclusão social dos indivíduos a partir de conceitos como empoderamento, libertação e emancipação ${ }^{5}$.MÉTODO Utilizou-se neste trabalho dados provenientes da PNS (2013). Analisou-se a prevalência relativa à percepção do estado de saúde e à realização de exames preventivos (exame físico de mama, solicitação e realização de mamografia) nos últimos dois anos, estratificadas pela idade da mulher, região do país, situação de domicilio, cobertura de Estratégia de Saúde da Família (ESF), nível de instrução e renda. RESULTADOS McD apresentam, em geral, níveis de avaliação sobre a própria saúde mais baixos que aquelas sem deficiência, principalmente entre $\mathrm{McD}$ com menores rendas, negras, fora da força de trabalho, sem instrução, situadas no Nordeste, domiciliadas em zona rural e cobertas pela ESF. Quanto aos exames preventivos, as $\mathrm{McD}$ apresentam menor probabilidade de tê-los realizados nos últimos dois anos, comparadas àquelas sem deficiência, exceto por aquelas $\mathrm{McD}$ de até 35 anos, que apresentaram maior chance de terem realizado tais exames. $\mathrm{O}$ grupo das $\mathrm{McD}$ negras, em situação de domicílio rural, extrema pobreza, cobertura da ESF e situadas no Nordeste acompanhou a tendência de menores prevalências de realização de exames preventivos. CONCLUSÕES Os resultados remetem à equidade, conceito amplo na saúde pública, direcionando, ainda, para uma discussão de caráter ético. O dilema da iniquidade deve ser considerado a partir da categoria da bioética de proteção dos mais frágeis e desassistidos, envolvendo, também, uma discussão política acerca disso. Neste cenário, o estigma atua como fator de iniquidade, prejudicando o acesso aos serviços de saúde, deixando McD em preocupante desvantagem em seu exercício de cidadania.

\section{REFERÊNCIAS}

[1] Goffman E. Estigma - Notas sobre a manipulação da identidade deteriorada. Rio de Janeiro: Zahar; 1963.

[2] Parker R. Interseções entre estigma, preconceito e discriminação na saúde pública mundial. In: Monteiro S, Villela W, organizadores. Estigma e saúde. Rio de Janeiro: Fiocruz; 2013. p. 25-46.

[3] Nicolau Stella Maris, Schraiber Lilia Blima, Ayres José Ricardo de Carvalho Mesquita. Mulheres com deficiência e sua dupla vulnerabilidade: contribuições para a construção da integralidade em saúde. Ciênc. Saúde Coletiva [Internet]. 2013 Mar; 18 (3): 863-872

[4] Wilson K, Rosenberg MW. Accessibility and the Canadian health care system: squaring perceptions and realities. Health Policy. 2004;67(2):137-48

[5] Garrafa, V. Inclusão social no contexto político da bioética. Revista Brasileira de Bioética, Brasília, v. 1, n. 2, p. 122-132, abr./jun. 2005. 
